\title{
Suppressing series resistance in organic solar cells by oxygen plasma treatment
}

\author{
Chien-Hung Lin, ${ }^{1}$ Shao-Chin Tseng, ${ }^{2}$ Yuan-Kui Liu, ${ }^{2}$ Yian Tai, ${ }^{3}$ Surojit Chattopadhyay, ${ }^{4}$ \\ Chi-Feng Lin, ${ }^{1}$ Jiun-Haw Lee, ${ }^{1}$ Jih-Shang Hwang, ${ }^{2}$ Yung-Yu Hsu, ${ }^{3}$ Li-Chyong Chen, ${ }^{5, a}{ }^{\prime}$ \\ Wei-Chao Chen, ${ }^{6}$ and Kuei-Hsien Chen ${ }^{6, a)}$ \\ ${ }^{1}$ Graduate Institute of Photonics and Optoelectronics and Department of Electrical Engineering, \\ National Taiwan University, Taipei 106, Taiwan \\ ${ }^{2}$ Institute of Optoelectronic Sciences, National Taiwan Ocean University, Keelung 20224, Taiwan \\ ${ }^{3}$ Department of Chemical Engineering, National Taiwan University of Science and Technology, \\ Taipei 106, Taiwan \\ ${ }_{5}^{4}$ Institute of Biophotonics Engineering, National Yang-Ming University, Taipei 112, Taiwan \\ ${ }^{5}$ Center for Condensed Matter Science, National Taiwan University, Taipei 106, Taiwan \\ ${ }^{6}$ Institute of Atomic and Molecular Sciences, Academia Sinica, Taipei 106, Taiwan
}

(Received 13 April 2008; accepted 15 May 2008; published online 11 June 2008)

\begin{abstract}
We demonstrate a low series resistance contact of gold (anode)/zinc-phthalocyznine in a reverse organic photovoltaic device aided by oxygen plasma treatment. The power conversion efficiency appreciated from $0.2 \%$ to $2.13 \%$, post $\mathrm{O}_{2}$ plasma treatment, predominantly due to the reduction in the series resistance of the device. A depth profile of zinc from x-ray photoelectron spectroscopy study revealed a gold layer with graded zinc composition, instead of pure gold, to be an efficient hole-collector from the organic interface. The zinc alloying of the gold layer has clearly been promoted by the oxygen plasma treatment. (C) 2008 American Institute of Physics.
\end{abstract}

[DOI: $10.1063 / 1.2940236]$

Bilayer and hybrid heterojunction organic photovoltaics $(\mathrm{PVs})$ have recently been intensively investigated for a breakthrough in materials design or process that often limits its performance. ${ }^{1-5}$ The electronic properties at the organic/ metal interface is a key issue in organic electronic devices. For electron injection into or extraction out of the organic semiconductors, a metal with a suitable work function is preferred as the anode. The cathode side has also been modified by the strategic use of $\mathrm{Ca}, \mathrm{Mg}$, or $\mathrm{LiF}$. This technique has previously been used to enhance the electron injection in organic light emitting diodes ${ }^{6}$ and the electron extraction in polymer bulk heterojunction solar cells. ${ }^{7,8}$ Such modification of the cathode assisted in useful lowering of the work function of cathode material, such as $\mathrm{Al}^{9}{ }^{9}$ Materials design or selection, interface control, ${ }^{10}$ and even postfabrication processing have all shown to improve carrier generation in the active material and collection at both the electrodes.

In this communication, we demonstrate how to improve the contact of $\mathrm{Au}$ (anode)/zinc-phthalocyanine $(\mathrm{ZnPc})$ in an $\mathrm{Au} / \mathrm{ZnPc} / n-\mathrm{Si}$ organic/inorganic photovoltaic device by $\mathrm{O}_{2}$ plasma treatment. This technique can be used routinely to enhance performance in an organic heterojunction PV device. The biggest challenge facing these organic devices is the relatively poor charge extraction at the anode. $\mathrm{O}_{2}$ plasma treatment will be introduced for this purpose in the organic PV cell processing for performance enhancement. The devices used in this study have been fabricated on $n$-type silicon wafers having the following structure: $\mathrm{Au}(10 \mathrm{~nm}) / \mathrm{ZnPc}$ $(60 \mathrm{~nm}) / n$-Si $(525 \mu \mathrm{m}) / \mathrm{Al}(100 \mathrm{~nm})$. Of these Au, Al, and $\mathrm{ZnPc}$ layer were fabricated by evaporation methods. Typically, all the deposition processes were carried out in a multisource chamber at room temperature, a base pressure of 1

\footnotetext{
a) Authors to whom correspondence should be address. Electronic addresses:
} chenlc@ntu.edu.tw and chenhk@pub.iams.sinica.edu.tw. $\times 10^{-6}$ Torr and the deposition rate was controlled at $1 \AA / \mathrm{s}$. The active region in our test cell was $0.04 \mathrm{~cm}^{2}$. A postfabrication with $\mathrm{O}_{2}$ plasma for $20 \mathrm{~min}$, at power densities of 150 and $250 \mathrm{~mW} / \mathrm{cm}^{2}$ and $\mathrm{O}_{2}$ pressure of $200 \mathrm{mTorr}$, was used to modify the $\mathrm{Au} / \mathrm{ZnPc}$ surface to complete the device. The current-voltage $(J-V)$ characteristics of the solar cells in the dark and illuminated conditions $\left(100 \mathrm{~mW} \mathrm{~cm}^{-2}\right.$ AM $1.5 \mathrm{G}$ solar illumination, Thermal Oriel 500W solar simulator) were measured using a Keithley 236 Source-Measure meter. The x-ray photoelectron spectroscopy (XPS) (VG ESCA Scientific Theta Probe using $1486.6 \mathrm{eV} \mathrm{Al} K \alpha$ source) measurements were performed on the devices, before and after the $\mathrm{O}_{2}$ plasma treatments, to study the chemical composition of the device layers. The elemental depth profiling was performed using $\mathrm{Ar}^{+}$ion sputtering of the device layers at an energy of $0.2 \mathrm{keV}$.

The optical absorption/transmission spectrum of the individual components of the device is shown in Fig. 1(a). The illumination of the active region can be estimated from the transmission of the top Au layer which is $10 \mathrm{~nm}$ thick. The $\mathrm{Au}$ layer has a transmittance of $50 \pm 15 \%$ in the 400-800 nm spectral region. The incident photon-to-current collection efficiency (IPCE) spectrum of devices, defined as the number of photogenerated carriers per incident photon, with and without the oxygen plasma treatment is shown in Fig. 1(b). The Au transmittance dominates the IPCE spectrum, but the optical responses of the $\mathrm{ZnPc}$ or $\mathrm{Si}$ are not explicit in it. ${ }^{11}$ However, an enhancement in the IPCE with high power oxygen plasma treatment was observed.

A strong increase in photocurrent and fill factor $(\mathrm{FF})$ was observed in the devices upon modification by the $\mathrm{O}_{2}$ plasma as shown in Fig. 2. The short circuit current density $\left(J_{\mathrm{sc}}\right)$ was improved from 1.1 to $12.3 \mathrm{~mA} / \mathrm{cm}^{2}$ and the FF from $20.0 \%$ to $36.3 \%$ resulting in a net gain in the power conversion efficiency (PCE) from $0.21 \%$ to $2.1 \%$ via the $250 \mathrm{~mW} / \mathrm{cm}^{2}$ 


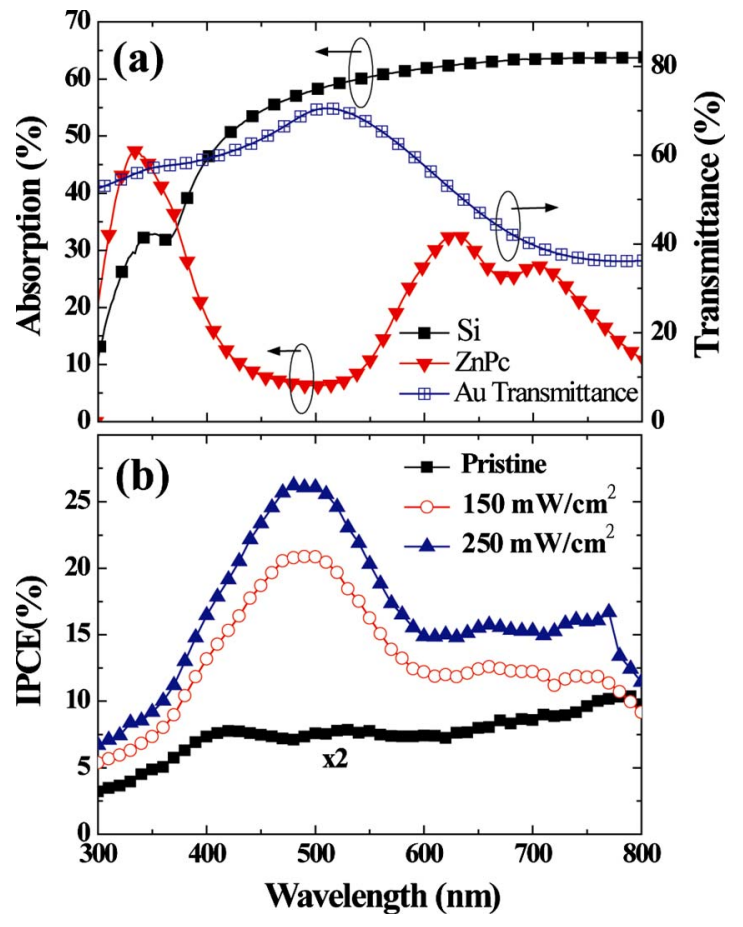

FIG. 1. (Color online) (a) The optical absorption/transmittance of the gold, $\mathrm{ZnPc}$, and silicon layers used in the photovoltaic cell. (b) The IPCE of the device, under short circuit conditions, with and without the oxygen plasma treatments.
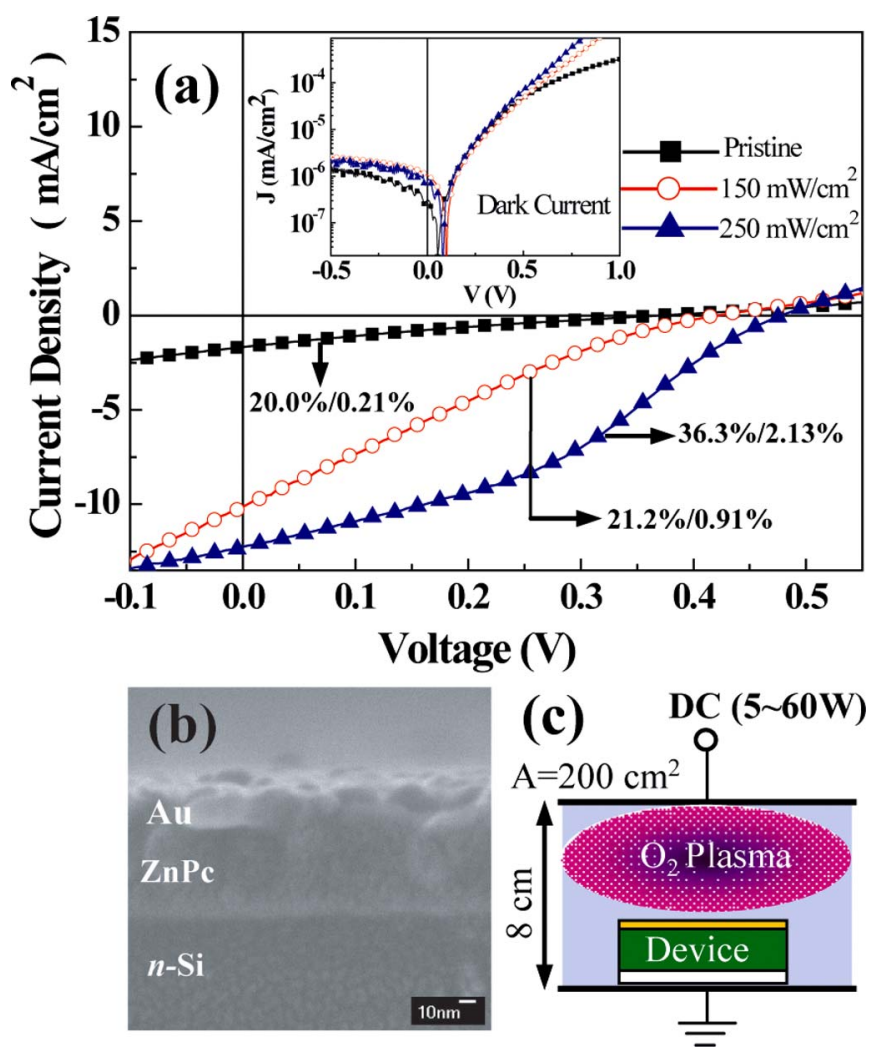

FIG. 2. (Color online) (a) The current density-voltage curve shows the performance of devices with and without oxygen plasma treatment. The numbers associated with each curve designate the FF/PCE (in order) of the particular device. The inset shows the current density-voltage curves under dark conditions. (b) The cross-sectional SEM image of the device structure showing the $\mathrm{Si} / \mathrm{ZnPc}$ and Au layer thickness. (c) A schematic of the dc

plasma system used to generate the $\mathrm{O}_{2}$ plasma.
Downloaded 06 Feb 2009 to 140.112 .113 .225 . Redistribution subject to AIP license $\mathrm{ZnPc}$ as we go deeper in the device. The Zn
(inght; see http://apl.aip.org/apl/copyright.jsp
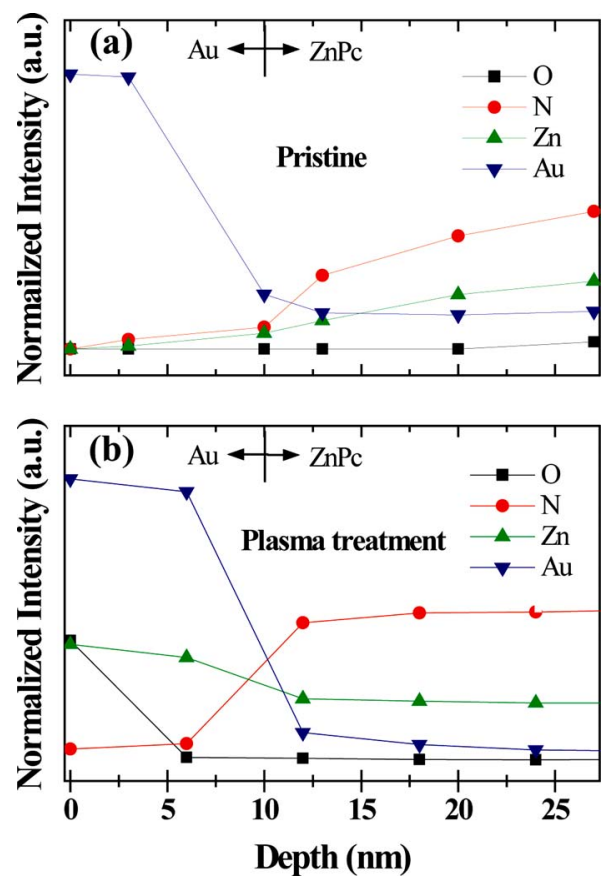

FIG. 3. (Color online) Comparison of the depth profile of oxygen, nitrogen, $\mathrm{Zn}$, and $\mathrm{Au}$ distribution from the Au surface to the $\mathrm{ZnPc}$ layer measured by XPS on device structures (a) without and (b) with $250 \mathrm{~mW} / \mathrm{cm}^{2} \mathrm{O}_{2}$ plasma treatment.

$\mathrm{O}_{2}$ plasma treatment. The dark current density (inset, Fig. 2), at any given forward bias, is maximum for the $250 \mathrm{~mW} / \mathrm{cm}^{2}$ plasma treated device and minimum for the untreated device. The injection current density improves with the plasma treatment corroborated by the decrease in series resistance from $37.25 \Omega$, for the untreated device, to $2.35 \Omega$ for the $250 \mathrm{~mW} / \mathrm{cm}^{2}$ plasma treated device. The improvement in the FF for the plasma treated devices could be attributed to this general reduction in the series resistance obtained from the slope of the $J-V$ curves under $V>V_{\mathrm{OC}}$ conditions. Although most of carriers are generated at the $n-\mathrm{Si} / \mathrm{ZnPc}$ interface, their collection is dependent on the contact resistance at the $\mathrm{Au} / \mathrm{ZnPc}$ interface. In order to understand the suppression in series resistance, a depth profile XPS of the devices was carried out.

A comparison of the elemental depth profile analysis in the untreated and $250 \mathrm{~mW} / \mathrm{cm}^{2}$ plasma treated device is shown in Figs. 3(a) and 3(b), respectively. A strong Au signal without free or bonded $\mathrm{Zn}$ contribution was found at the top (depth of $0-10 \mathrm{~nm}$ ) of the untreated device [Fig. 3(a)]. In comparison, the plasma treated device shows substantial $\mathrm{Zn}$ $2 p_{3 / 2}$ signal in the top Au layer. Nitrogen and $\mathrm{Zn}$, originating from the $\mathrm{ZnPc}$ layer, dominate the XPS spectra beyond a depth of $10 \mathrm{~nm}$ with feeble signals from $\mathrm{O}$ and $\mathrm{Au}$ as expected. It was compelling to study why this $\mathrm{Zn}$ alloyed $\mathrm{Au}$ layer, or an Au layer with $\mathrm{Zn}$ impurities, if we may say so, gave better PV performance than the pure Au layer itself in the untreated device.

A careful look at the $\mathrm{Zn} 2 p_{3 / 2}$ XPS depth profile spectra of the $\mathrm{O}_{2}$ plasma treated $\left(250 \mathrm{~mW} / \mathrm{cm}^{2}\right)$ device (Fig. 4) revealed the existence of both metallic $\mathrm{Zn}, \mathrm{Zn}^{0}$ at a binding energy of $1021.7 \mathrm{eV}$, and $\mathrm{Zn}$ bonded with nitrogen as in $\mathrm{ZnPc}, \mathrm{Zn}^{2+}$ at a binding energy of $1022.6 \mathrm{eV}$. The Au subsurface yielded free metallic $\mathrm{Zn}$ signal at $1021.7 \mathrm{eV}$ which shifts to higher binding energies corresponding to $\mathrm{Zn}-\mathrm{N}$ bonding in $\mathrm{ZnPc}$ as we go deeper in the device. The $\mathrm{Zn}$ 


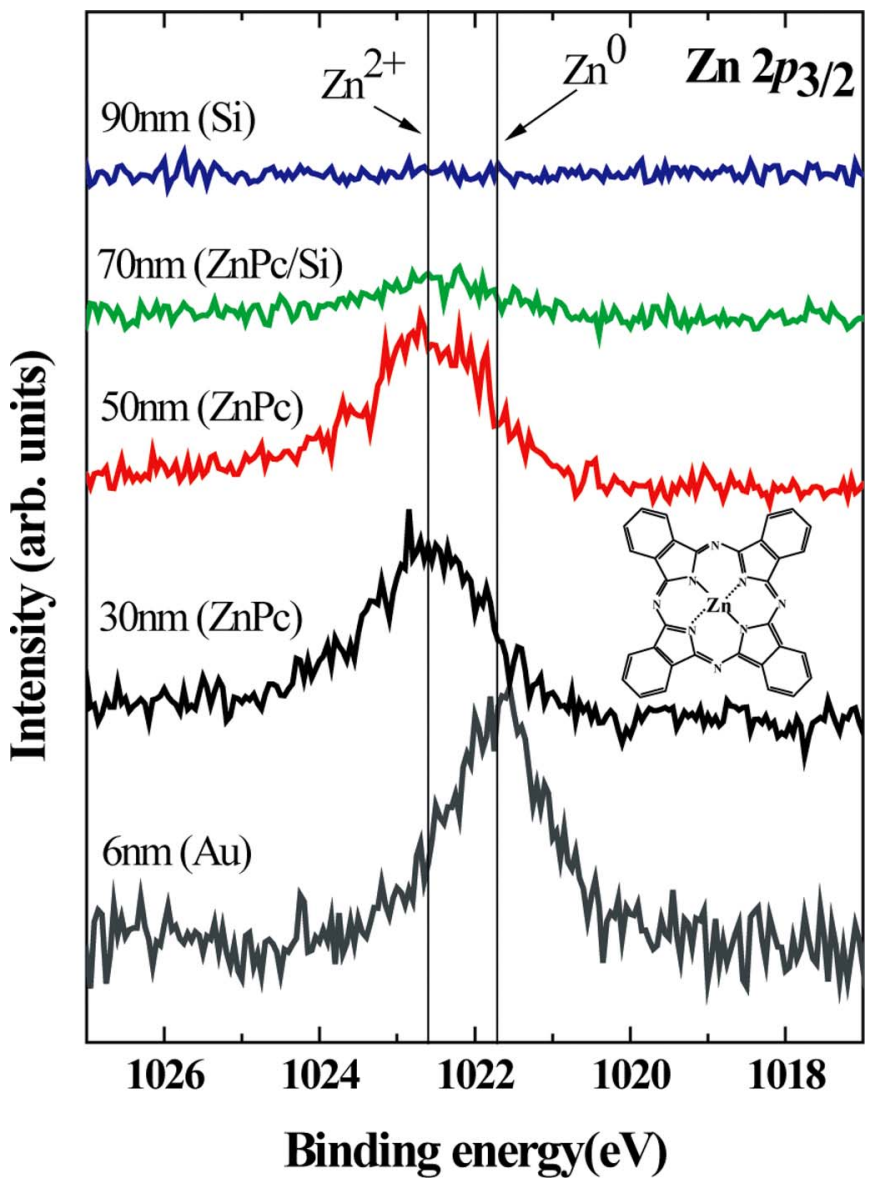

FIG. 4. (Color online) A depth profile of the $\mathrm{Zn} 2 p_{3 / 2}$ core level XPS spectra of the device after $\mathrm{O}_{2}$ plasma treatment of $250 \mathrm{~mW} / \mathrm{cm}^{2}$. The plots show the variation of the $\mathrm{Zn}$ signal through the top Au layer deep into the silicon substrate.

signal vanishes as we reach the $n$-Si at the bottom of the device. The result suggests a decomposition of the $\mathrm{ZnPc}$ near $\mathrm{Au}$ interface due to the oxygen plasma treatment and an out diffusion of elemental $\mathrm{Zn}$ in the Au layer. The pure Au anode in the untreated device is now replaced with an $\mathrm{Au}$ layer, with a graded $\mathrm{Zn}$ composition, in the $\mathrm{O}_{2}$ plasma treated device.

The originally sharp $\mathrm{Au} / \mathrm{ZnPc}$ interface is electrically weak for the hole extraction ${ }^{12}$ and shows a space charge trapping in the organic layer reflected in the poor FF, and higher series resistance at the forward bias. The situation at the $\mathrm{Au}$ subsurface changes with the $\mathrm{O}_{2}$ plasma treatment as free metallic $\mathrm{Zn}$ distributes itself within the Au layer with a composition gradient down to the $\mathrm{Au}-\mathrm{ZnPc}$ interface. This hypothesis is supported by experimental observations of reduced series resistances even by using coevaporated Au and pthalocyanine in the device structure (result not shown). However, coevaporation is inferior to the oxygen plasma treatment since the former results in bulk mixing of $\mathrm{Au}$ and $\mathrm{ZnPc}$ unlike the controlled interfacial metallic interdiffusion in the latter. Introduction of defect states intermediate to the $\mathrm{Au}$ Fermi level (at $5.1 \mathrm{eV}$ ) and highest occupied molecular orbital in $\mathrm{ZnPc}$ (at $5.28 \mathrm{eV}$ ) may provide hopping pathways for the hole towards the anode. This in turn could have modified the absorption of the $\mathrm{ZnPc}$ in the 400-600 nm range. The power of $\mathrm{O}_{2}$ plasma used ensures that the bulk of $\mathrm{ZnPc}$ retains the chemical integrity. In conclusion, oxygen plasma treatment was used to reduce the electrical resistance at the anode contact of an organic-inorganic solar cell device that translated into an efficiency gain of about an order in magnitude.

${ }^{1}$ C. W. Tang, Appl. Phys. Lett. 48, 183 (1986).

${ }^{2}$ P. Peumans and S. R. Forrest, Appl. Phys. Lett. 79, 126 (2001).

${ }^{3}$ J. Xue, B. P. Rand, S. Uchida, and S. R. Forrest, Adv. Mater. (Weinheim, Ger.) 17, 66 (2005).

${ }^{4} \mathrm{G}$. Li, V. Shrotriya, J. Huang, Y. Yao, T. Moriarty, K. Emery, and Y. Yang, Nat. Mater. 4, 864 (2005).

${ }^{5}$ J. Y. Kim, S. H. Kim, H.-H. Lee, K. Lee, W. Ma, X. Gong, and A. J. Heeger, Adv. Mater. (Weinheim, Ger.) 18, 572 (2006).

${ }^{6}$ S. E. Shaheen, G. E. Jabbour, M. M. Morrell, Y. Kawabe, B. Kippelen, N. Peyghambarian, M.-F. Nabor, R. Schlaf, E. A. Mash, and N. R. Armstrong, J. Appl. Phys. 84, 2324 (1998).

${ }^{7}$ C. J. Brabec, S. E. Shaheen, C. Winder, N. S. Sariciftci, and P. Denk, Appl. Phys. Lett. 80, 1288 (2002).

${ }^{8}$ E. Ahlswede, J. Hanisch, and M. Powalla, Appl. Phys. Lett. 90, 163504 (2007).

${ }^{9}$ S. Yamaguchi, R. Izaki, K.-I. Yamagiwa, K. Taki, Y. Iwamura, and A. Yamamoto, Appl. Phys. Lett. 835398 (2003).

${ }^{10}$ C. H. Lin, S. Chattopadhyay, C. W. Hsu, M. H. Wu, W. C. Chen, C. T. Wu, S. C. Tsen, J. S. Hwang, J. H. Lee, C. H. Chen, L. C. Chen, and K. H. Chen (unpublished).

${ }^{11}$ H. Tanaka, T. Yasuda, K. Fujita, and T. Tsutsui, Adv. Mater. (Weinheim, Ger.) 18, 2230 (2006).

${ }^{12}$ W. Chen, L. Wang, D. C. Qi, S. Chen, X. Y. Gao, and A. T. S. Wee, Appl. Phys. Lett. 88, 184102 (2006). 